\title{
Preoperative adjuvant therapy for locally advanced and recurrent/metastatic gastrointestinal stromal tumors: a retrospective study
}

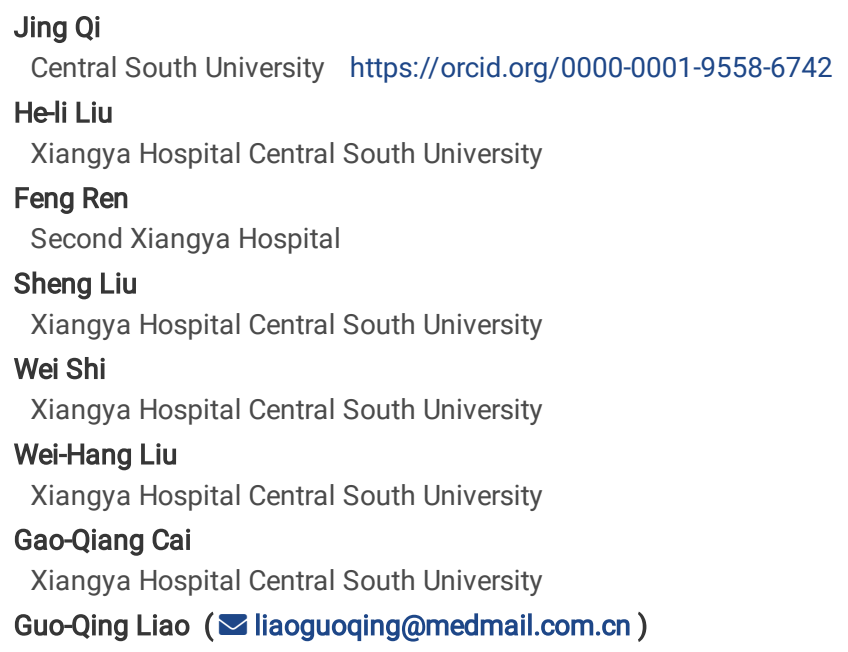

Version of Record: A version of this preprint was published at World Journal of Surgical Oncology on April 7th, 2020. See the published version at https://doi.org/10.1186/s12957-020-01840-9. 


\section{Abstract}

Background

Preoperative imatinib mesylate therapy for gastrointestinal stromal tumors (GISTs) is controversial. This study aimed to explore the clinical efficacy and optimal duration of preoperative imatinib mesylate (IM) therapy in patients with locally advanced and recurrent/metastatic GISTs.

Methods

We retrospectively examined patients who received preoperative imatinib mesylate therapy from January 2013 to December 2018 at Xiangya Hospital, Central South University and the Second Xiangya Hospital of Central South University, China. Clinical data, including the results of tests for mutations in KIT and PDGFR, findings from regularly conducted re-examinations, abdominal enhanced computed tomography/magnetic resonance imaging data, responses to imatinib, progression-free survival and overall cancer-specific survival, were recorded.

Results

A total of 25 patients were enrolled in our study, including 18 with a locally advanced GIST and 7 with recurrent or metastatic GISTs. Their ages ranged from 22 to 70 years $(M: F=1.6: 0.9)$, with a mean age of $50.48 \pm 12.51$ years. The tumor locations included the stomach (56.0\%), rectum (16.0\%), enterocoelic/retroperitoneal sites (12.0\%) and the small intestine (12.0\%). Based on testing for mutations in KIT and PDGFR, 22 patients received 400 mg/d $\mathrm{KIT}$, and 3 patients received $600 \mathrm{mg} / \mathrm{d}$ PDGFR. The median duration of preoperative IM therapy was $8.96 \pm 4.81$ months, ranging from 3 to 26 months. According to the Choi criteria, 24 patients achieved a partial response (PR), and 1 patient had stable disease (SD). All patients underwent surgery after preoperative IM therapy, and no postoperative complications appeared. The 2-year PFS and 5-year PFS were $92 \%$ and $60 \%$, respectively, and the total 5-year cancer-specific survival (CSS) was $92 \%$.

Conclusion

Preoperative imatinib therapy is feasible for locally advanced and recurrent/metastatic GISTs and can effectively shrink the tumor size, allow organ sparing and avoid extensive organ resection. Moreover, the optimal duration of preoperative IM therapy in patients with locally advanced and recurrent/metastatic GISTs was $8.96 \pm 4.81$ months, ranging from 3 to 26 months, and gastric GISTs had a better response to preoperative IM therapy than did non-gastric GISTs.

\section{Backgrounds:}

Gastrointestinal stromal tumors (GISTs) are the most common primary mesenchymal tumors occurring throughout the gastrointestinal tract, with an annual incidence of approximately 7 to 15 per million inhabitants per year and accounting for approximately 1 to $3 \%$ of all malignant gastrointestinal tumors[1, 2]. GISTs occur most frequently in the stomach and small intestine[3]. Total tumor resection is the only curative option and the basis of GIST treatment. However, up to $20 \%$ of GIST patients have metastases at diagnosis [4], most commonly in the abdominal cavity, liver, lungs, bones and other rare organs. Lymph node metastases are uncommon clinical features in GISTs, except for pediatric GISTs, pediatric-type GISTs in young adults and syndromic GISTs [5].

The diagnosis of GISTs depends on the immunohistochemistry of tumor tissues and gene mutation analysis. Most GISTs stain for KIT protein (CD117; 95\%) [6] and anoctamin-1 (DOG-1; 98\%)[7], but most do not stain for desmin, a biomarker of smooth muscle tumors. Moreover, approximately 75\% of GISTs have a mutation in KIT occurring in exons 9 (8\%), 11 (90\%), 13 (1\%) and 17 (1\%), and 10-20\% of GISTs have a mutation in platelet-derived growth factor receptor A (PDGFRA) occurring in exons 12, 14 and 18[8, 9], which encode type III receptor tyrosine kinase and are the cornerstone for the receptor tyrosine kinase inhibitors (RTKIs) applied in GIST patients[10].

Before receptor tyrosine kinase inhibitors (RTKIs) were applied in GISTs, the survival rate was still poor despite the resection of primary GIST tumors [11]. Imatinib mesylate (IM), a typical type of RTKI, dramatically improves the prognosis of GISTs, especially in metastatic/recurrent GISTs [12]. Surgery combined with adjuvant IM has greatly improved the prognosis of patients with intermediate or high-risk categories according to revised National Institutes of Health $(\mathrm{NIH})$ guidelines (2008). Even so, when the tumor sizes are too large or the tumor locations are special (e.g., cardia of the stomach, duodenal nipple or rectum), up-front surgical resection should be deeply considered because it might excise surrounding organs and lead to an extensive R0 organ resection procedure (e.g., total gastrectomy, pancreaticoduodenectomy or abdominoperineal excision of the rectum); such treatment would eventually lead to permanent changes in the patient's lifestyle or increase the operative morbidity. In that case, imatinib mesylate (IM) is the only TKI that has been studied as adjuvant therapy at a dosage of $400 \mathrm{mg} / \mathrm{d}$, which aims to shrink the tumor size and preserve the surrounding organs to the greatest extent[13, 14].

However, the optimal duration of preoperative imatinib is still unknown, and it is always recommended for 6 to 12 months to shrink the tumor size after IM initiation. Multidisciplinary team members should cooperate to monitor the response to IM and determine the optimal operation time for those patients. In addition, both 6 months of preoperative IM therapy and surveillance when tumor size shrinkage is detected by consecutive radiographic imaging in metastatic/recurrent GISTs are suggested[15, 16], but the survival benefit from an operation following IM therapy cannot be determined. Hence, our study aimed to explore the clinical efficacy and the optimal duration of preoperative IM therapy in patients with locally advanced and recurrent/metastatic GISTs.

\section{Methods}

\section{Patient selection}


GIST patients were collected through a pathology information system and were diagnosed from January 2013 to December 2018 at Xiangya Hospital, Central South University and the second Xiangya Hospital of Central South University. Further clinical information and clinical follow-up data were collected by our clinical system and communication with patients. The eligibility criteria in this study included the following: (1) patients were pathologically confirmed as having locally advanced or recurrent/metastatic GISTs by morphology and immunohistochemical staining, and the specimens were obtained by fine needle biopsy, surgery or endoscopy; (2) GISTs were assessed as unresectable or as needing extensive organ resections for R0 resection, as evaluated by our multidisciplinary team including experienced oncologists, surgeons, pathologists and radiologists; (3) all GIST patients had no history of radiotherapy and chemotherapy before taking preoperative IM therapy; and (4) the Eastern Cooperative Oncology Group performance status score was 0 or 1 . The exclusion criteria were as follows: (1) GISTs showed primary resistance to IM by mutation analysis or radiographic imaging; (2) patients could not tolerate operation or IM therapy; and (3) patients refused to take preoperative IM therapy and strongly required surgery directly. This retrospective study was supported by the Medical Ethics Committee of Xiangya Hospital, Central South University (No. 201909812), and due to the retrospective nature of the study, informed consent was waived.

\section{Preoperative Procedure}

The preoperative procedure was managed by a multidisciplinary team comprising oncologists, surgeons, pathologists and radiologists. GIST specimens were collected by fine needle biopsy, surgery or endoscopy, formalin-fixed, paraffin-embedded and diagnosed by microscopic morphology and

immunohistochemistry for CD117, DOG-1 and desmin. The initial dosage of IM was based on the results of the mutation analysis. Patients who had KIT exon 9 mutations were administered a dosage of $600 \mathrm{mg}$ once daily, others received $400 \mathrm{mg}$ once daily, and close monitoring was performed to assess them by contrast-enhanced computerized tomography (CT) scans or contrast-enhanced magnetic resonance imaging (MRI) scans. The multidisciplinary team discussed and evaluated the optimal timing for surgical resection. IM therapy was discontinued immediately before surgical resection.

\section{Therapeutic Assessment}

Contrast-enhanced CT scans or contrast-enhanced MRI scans were performed to monitor tumor progression; initial scans were conducted before IM therapy, and follow-up CT or MRI scans were performed every 3 months. The response of the target lesions was evaluated according to the Choi criteria[17]. The plateau response was defined at the point in the sum of diameters of target lesion shrinkage between $10 \%$ decrease and $10 \%$ increase, with a decrease in tumor density (HU) of less than $15 \%$, detected by two consecutive radiographic images. The total response was classified according to Choi criteria as complete response (CR), partial response (PR), progressive disease (PD), and stable disease (SD).

\section{Operation Timing And Postoperative Therapy}

The optimal operation timing was as follows: (1) two consecutive radiographic images indicated that the tumor response was at the plateau; (2) the multidisciplinary team discussed and evaluated a meaningful downstaging, including converting the total gastrectomy to local tumor resection, converting the pancreaticoduodenectomy (Whipple operation) to local excision and converting abdominoperineal resection with permanent end colostomy to a sphincter-sparing transanal resection; (3) patients could not tolerate the side effects and directly demanded surgical treatment; and (4) patients exhibited massive alimentary tract bleeding or gastrointestinal perforation that required an emergency operation.

Postoperative IM adjuvant treatment at a dosage of $400 \mathrm{mg} / \mathrm{d}$ or $600 \mathrm{mg} / \mathrm{d}$ was restarted as soon as the patients were able to tolerate oral medications, patients with nonmetastatic tumors that were locally advanced or in special locations were treated with R0 resection and continued imatinib adjuvant treatment for 36 months in total; patients with recurrent/metastatic GISTs continued imatinib adjuvant treatment until the follow-up period ended. The last follow-up was considered performed in October 2019 or prior to patient death for any cause.

\section{Statistical Analysis}

The counting data are shown as percentages, and measurement data are shown as the mean or median with standard deviation (SD). Progression-free survival (PFS) and cancer-specific survival (CSS) were obtained by the Kaplan-Meier method. Statistical analysis was performed using SPSS V19.0 (SPSS, Inc., USA).

\section{Results}

\section{Demographic data and clinicopathologic data}

A total of 29 patients were enrolled in our study; however, one patient refused to join our research, and one patient did not undergo operative IM therapy because the gene mutation analysis showed a PDGFRA exon 18 D842V mutation. One patient did not tolerate the IM side effects and refused subsequent therapy, and one patient refused to undergo surgery until the end of the follow-up. Therefore, an effective analysis of preoperative IM therapy was conducted in the remaining 25 patients (Fig. 1). The analytic cohort of 25 patients had a mean age of $50.48 \pm 12.51$ years, ranging from 22 to 70 years, comprising 16 (64.0\%) men and $9(36.0 \%)$ women. Of all patients, 18 had locally advanced GISTs, and 7 had recurrent or metastatic GISTs. The pretreatment maximum diameter of each GIST was measured by CT and MRI scans, with an average of $11.48 \pm 4.46$ centimeters (cm), ranging from 4.5 to $22.4 \mathrm{~cm}$. The analytic cohort tumors were located in the stomach (56.0\%), small intestine (16.0\%), rectum (16.0\%) and enterocoelic/retroperitoneum (12.0\%). All patients underwent gene mutation analysis, and the results showed that 3 patients had KIT exon 9 mutations, 18 patients had KIT exon 11 mutations, 1 patient had KIT exon 11 
and exon 13 mutations, one patient had KIT exon 17 mutations, and 2 patients had no mutations in either KIT or PDGFRA, which were called wild-type GISTs (WT-GISTs). More clinical and pathological data are shown in Table 1.

\begin{tabular}{|c|c|c|}
\hline Characteristics & & Patients $\mathrm{n}(\%)$ or mean \pm SD \\
\hline Median age, years [range] & & $50.48 \pm 12.51[22-70]$ \\
\hline \multirow[t]{2}{*}{ Gender } & Male & $16(64.0 \%)$ \\
\hline & Female & $9(36.0 \%)$ \\
\hline \multirow[t]{2}{*}{ Classify of preoperative therapy } & IM therapy in locally advanced GISTs & $18(72.0 \%)$ \\
\hline & IM therapy in recurrent/metastasis GISTs & $7(28.0 \%)$ \\
\hline \multirow[t]{5}{*}{ Primary localization } & Stomach & $14(56.0 \%)$ \\
\hline & Duodenum & $4(16.0 \%)$ \\
\hline & Jejuno-ileum & $1(4.0 \%)$ \\
\hline & Rectum & $4(16.0 \%)$ \\
\hline & Pelvic/retroperitoneal & $2(8.0 \%)$ \\
\hline \multirow[t]{2}{*}{ Dose of IM therapy } & $400 \mathrm{mg} / \mathrm{d}$ & $22(88.0 \%)$ \\
\hline & $600 \mathrm{mg} / \mathrm{d}$ & $3(12.0 \%)$ \\
\hline Duration of preoperative therapy ,months[range] & & $8.96 \pm 4.81[3-26]$ \\
\hline Preoperative maximal dimension, cm[range] & & $11.48 \pm 4.46[4.5-24.4]$ \\
\hline \multirow[t]{6}{*}{ Gene mutation, wild type vs. mutation } & Kit in exon 9 & 22 vs. 3 \\
\hline & Kit in exon 11 & 6 vs. 19 \\
\hline & Kit in exon 13 & 24 vs. 1 \\
\hline & Kit in exon 17 & 24 vs. 1 \\
\hline & PDGFRA in exon 12 & 25 vs. 0 \\
\hline & PDGFRA in exon 18(D842V) & 25 vs. 0 \\
\hline \multirow[t]{2}{*}{ Numbers of lesions } & Single & $19(76.0 \%)$ \\
\hline & Multiple & $6(24.0 \%)$ \\
\hline \multirow[t]{3}{*}{ Response to IM therapy(according to Choi criteria) } & PR & $24(96.0 \%)$ \\
\hline & SD & $1(4.0 \%)$ \\
\hline & PD & $0(0.0 \%)$ \\
\hline \multirow[t]{3}{*}{ Margin status } & Ro & $24(96.0 \%)$ \\
\hline & $\mathrm{R} 1$ & $0(0.0 \%)$ \\
\hline & $\mathrm{R} 2$ & $1(4.0 \%)$ \\
\hline \multirow[t]{2}{*}{ ECOG performance status } & 0 & $18(72.0 \%)$ \\
\hline & 1 & $7(28.0 \%)$ \\
\hline
\end{tabular}

\section{Clinical Efficacy To IM Therapy}

Based on the mutation analysis, 3 patients with KIT exon 9 mutations were administered the dosage of 600 mg once daily, and the other 22 patients were administered at the dosage of $400 \mathrm{mg}$ once daily. According to the Choi criteria, 24 patients achieved a partial response (PR), and 1 patient developed a stable disease (SD) and received surgery immediately after completing 4 months of preoperative IM treatment; the mutation analysis showed a wild-type GIST (Fig. 2). All patients underwent surgery after preoperative IM therapy, and 24 patients achieved effective shrinkage of the tumor size to various extents, with sizes decreasing from $11.48 \pm 4.46 \mathrm{~cm}$ to $8.24 \pm 4.02 \mathrm{~cm}(\mathrm{P} \leq 0.001)$. All patients underwent surgery after preoperative IM therapy. Fourteen gastric GIST patients underwent preoperative therapy. One of them achieved an SD response and underwent proximal gastrectomy (R0 resection) after 4 months of preoperative IM treatment. Ten patients who were assessed to perform total gastrectomy before IM therapy by our multidisciplinary team finally underwent partial gastrectomy (R0 resection) after preoperative IM treatment, including 3 patients who underwent laparoscopic partial gastrectomy and 3 patients who 
were assessed for unresectable tumors because of a large recurrent tumor size or metastasis to the liver and finally underwent partial gastrectomy (R0 or R2 resection). Two patients in five small intestine GIST patients finally underwent pancreaticoduodenectomy (R0 resection) because the tumors were too near to the duodenal papilla, 1 patient who was assessed to perform pancreaticoduodenectomy before IM therapy finally underwent partial duodenum resection (R0 resection) after preoperative IM treatment, and 2 patients with small intestine metastasis/recurrent GISTs who were considered unresectable before IM therapy underwent local resection of the liver and tumor resection combined with partial small bowel resection (R0 resection). Four rectal GIST patients underwent preoperative therapy, two finally underwent laparoscopic abdominoperineal resection (R0 resection), and the other 2 patients who were assessed for abdominoperineal resection finally underwent transanal minimally invasive surgery and sphincter-sparing resection (R0 resection), respectively. The remaining two pelvic/retroperitoneal GIST patients who received preoperative therapy and had been considered unresectable before IM therapy finally underwent tumor resection due to the shrinkage of tumor sizes after preoperative IM therapy. No postoperative complications occurred in our study group patients (Table 2). 


\begin{tabular}{|c|c|c|c|c|c|c|c|c|c|}
\hline \multirow[b]{2}{*}{ No. } & \multicolumn{3}{|c|}{ General information } & \multicolumn{3}{|c|}{ Preoperative IM therapy } & \multicolumn{3}{|l|}{ Operation } \\
\hline & $\begin{array}{l}\mathrm{G} / \mathrm{A} \\
\text { (years) }\end{array}$ & Tumor location & $\begin{array}{l}\text { Mutation } \\
\text { analysis }\end{array}$ & $P / R$ & $\begin{array}{l}\text { Dose } \\
(\mathrm{mg} / \mathrm{d})\end{array}$ & $\begin{array}{l}\text { Duration } \\
\text { (months) }\end{array}$ & $\begin{array}{l}\text { Assessed before IM } \\
\text { therapy }\end{array}$ & Performing after IM therapy & $\begin{array}{l}\text { Margin } \\
\text { status }\end{array}$ \\
\hline 1 & $\mathrm{~F} / 50$ & Stomach & $\begin{array}{l}\text { Kit E11 } \\
\text { mut. }\end{array}$ & $P$ & 400 & 4 & total gastrectomy & $\begin{array}{l}\text { Partial gastrectomy } \\
\text { combined with spleen } \\
\text { resection }\end{array}$ & Ro \\
\hline 2 & $\mathrm{M} / 50$ & Stomach & $\begin{array}{l}\text { Kit E11 } \\
\text { mut. }\end{array}$ & $P$ & 400 & 6 & total gastrectomy & $\begin{array}{l}\text { Partial } \\
\text { gastrectomy(Laparoscopic) }\end{array}$ & Ro \\
\hline 3 & $\mathrm{M} / 48$ & Stomach & $\begin{array}{l}\text { Kit E11 } \\
\text { mut. }\end{array}$ & $P$ & 400 & 6 & total gastrectomy & $\begin{array}{l}\text { Partial } \\
\text { gastrectomy(Laparoscopic) }\end{array}$ & Ro \\
\hline 4 & $M / 63$ & Stomach & $\begin{array}{l}\text { Kit E11 } \\
\text { mut. }\end{array}$ & $\mathrm{P}$ & 400 & 3 & total gastrectomy & Partial gastrectomy & Ro \\
\hline 5 & $\mathrm{~F} / 65$ & Stomach & $\begin{array}{l}\text { Kit E11 } \\
\text { mut. }\end{array}$ & $P$ & 400 & 7 & total gastrectomy & $\begin{array}{l}\text { Partial } \\
\text { gastrectomy(Laparoscopic) }\end{array}$ & Ro \\
\hline 6 & $M / 59$ & Stomach & $\begin{array}{l}\text { Wild- } \\
\text { type }\end{array}$ & $P$ & 400 & 4 & proximal gastrectomy & proximal gastrectomy & Ro \\
\hline 7 & $F / 68$ & Stomach & $\begin{array}{l}\text { Kit E11 } \\
\text { and E13 } \\
\text { mut. }\end{array}$ & $\mathrm{P}$ & 400 & 7 & total gastrectomy & Partial gastrectomy & Ro \\
\hline 8 & $\mathrm{M} / 58$ & Stomach and liver & $\begin{array}{l}\text { Kit E11 } \\
\text { mut. }\end{array}$ & $\mathrm{R}$ & 400 & 8 & Unresectable & $\begin{array}{l}\text { Partial gastrectomy } \\
\text { combined with spleen } \\
\text { resection }\end{array}$ & $\mathrm{R} 2$ \\
\hline 9 & $\mathrm{M} / 70$ & Stomach & $\begin{array}{l}\text { Kit E11 } \\
\text { mut. }\end{array}$ & $\mathrm{P}$ & 400 & 12 & total gastrectomy & Partial gastrectomy & Ro \\
\hline 10 & $M / 58$ & Stomach & $\begin{array}{l}\text { Kit E11 } \\
\text { mut. }\end{array}$ & $\mathrm{R}$ & 400 & 26 & Unresectable & Partial gastrectomy & Ro \\
\hline 11 & $\mathrm{~F} / 44$ & Stomach & $\begin{array}{l}\text { Kit E11 } \\
\text { mut. }\end{array}$ & $P$ & 400 & 11 & total gastrectomy & Partial gastrectomy & Ro \\
\hline 12 & $\mathrm{~F} / 31$ & Stomach & $\begin{array}{l}\text { Kit E11 } \\
\text { mut. }\end{array}$ & $\mathrm{R}$ & 400 & 8 & Unresectable & Partial gastrectomy & Ro \\
\hline 13 & $\mathrm{~F} / 22$ & Stomach & $\begin{array}{l}\text { Kit E11 } \\
\text { mut. }\end{array}$ & $P$ & 400 & 10 & total gastrectomy & Partial gastrectomy & Ro \\
\hline 14 & $\mathrm{~F} / 40$ & Stomach & $\begin{array}{l}\text { Kit E11 } \\
\text { mut. }\end{array}$ & $\mathrm{P}$ & 400 & 9 & total gastrectomy & Partial gastrectomy & Ro \\
\hline 15 & $\mathrm{M} / 46$ & small intestine & $\begin{array}{l}\text { Wild- } \\
\text { type }\end{array}$ & $P$ & 400 & 9 & pancreaticoduodenectomy & pancreaticoduodenectomy & Ro \\
\hline 16 & $\mathrm{~F} / 53$ & small intestine & $\begin{array}{l}\text { Kit E9 } \\
\text { mut. }\end{array}$ & $P$ & 600 & 4 & pancreaticoduodenectomy & partial duodenum resection & Ro \\
\hline 17 & $M / 38$ & small intestine & $\begin{array}{l}\text { Kit E11 } \\
\text { mut. }\end{array}$ & $P$ & 400 & 7 & pancreaticoduodenectomy & pancreaticoduodenectomy & Ro \\
\hline 18 & $\mathrm{M} / 67$ & small intestine & $\begin{array}{l}\text { Kit E9 } \\
\text { mut. }\end{array}$ & $\mathrm{R}$ & 600 & 10 & Unresectable & local resection of liver & Ro \\
\hline 19 & $\mathrm{M} / 47$ & small intestine & $\begin{array}{l}\text { Kit E9 } \\
\text { mut. }\end{array}$ & $\mathrm{R}$ & 600 & 8 & Unresectable & $\begin{array}{l}\text { Tumor resection combined } \\
\text { with partial small bowel } \\
\text { resection }\end{array}$ & Ro \\
\hline 20 & $M / 65$ & Rectum & $\begin{array}{l}\text { Kit E11 } \\
\text { mut. }\end{array}$ & $\mathrm{P}$ & 400 & 12 & $\begin{array}{l}\text { Abdominoperineal } \\
\text { resection }\end{array}$ & $\begin{array}{l}\text { Abdominoperineal } \\
\text { resection(laparoscopic) }\end{array}$ & Ro \\
\hline 21 & $\mathrm{M} / 48$ & Rectum & $\begin{array}{l}\text { Kit E11 } \\
\text { mut. }\end{array}$ & $\mathrm{P}$ & 400 & 7 & $\begin{array}{l}\text { Abdominoperineal } \\
\text { resection }\end{array}$ & $\begin{array}{l}\text { Transanal minimally } \\
\text { invasive surgery }\end{array}$ & Ro \\
\hline 22 & $\mathrm{~F} / 32$ & Rectum & $\begin{array}{l}\text { Kit E11 } \\
\text { mut. }\end{array}$ & $\mathrm{P}$ & 400 & 9 & $\begin{array}{l}\text { Abdominoperineal } \\
\text { resection }\end{array}$ & Sphincter-sparing resection & Ro \\
\hline 23 & $\mathrm{M} / 54$ & Rectum & $\begin{array}{l}\text { Kit E17 } \\
\text { mut. }\end{array}$ & $P$ & 400 & 12 & $\begin{array}{l}\text { Abdominoperineal } \\
\text { resection }\end{array}$ & $\begin{array}{l}\text { Abdominoperineal } \\
\text { resection(laparoscopic) }\end{array}$ & Ro \\
\hline 24 & $M / 46$ & Pelvic/retroperitoneal & $\begin{array}{l}\text { Kit E11 } \\
\text { mut. }\end{array}$ & $\mathrm{R}$ & 400 & 18 & Unresectable & $\begin{array}{l}\text { retroperitoneal tumor } \\
\text { resection }\end{array}$ & Ro \\
\hline 25 & $\mathrm{M} / 40$ & Pelvic/retroperitoneal & $\begin{array}{l}\text { Kit E11 } \\
\text { mut. }\end{array}$ & $\mathrm{R}$ & 400 & 7 & Unresectable & pelvic tumor resection & Ro \\
\hline
\end{tabular}




\section{Optimal Duration Of Preoperative IM Therapy}

We found that the duration of preoperative IM therapy was associated with tumor localization. Gastric GISTs was treated with a median duration of 8.64 months, and small intestine GIST patients underwent preoperative IM therapy with a median duration of 7.6 months; however, treatment for GISTs located in the rectum and pelvis/retroperitoneum seemed to have a longer duration, with a median duration of 10.0 months and 12.5 months, respectively. The total cases were administered preoperative IM therapy with a median duration of 8.96 months (Figure 3).

We found that the mean duration of preoperative IM therapy was 8.96 months. To further investigate the data, we divided GIST patients into groups that received IM therapy for less than 8.96 months and more than 8.96 months. As shown in Table 3, we found that there were no significant differences in characteristics between the groups; however, it seems that tumors located in the stomach and small intestine had a shorter duration than those located in the rectum or pelvis/retroperitoneum, indicating that the upper gastrointestinal tract might have a better response and shorter duration of IM therapy. Due to the limited cases in our retrospective study, there were no significant differences between the two groups.

Table 3. Characteristics of GIST patients with different duration of preoperative IM therapy $(n=26)$

\begin{tabular}{|c|c|c|c|c|}
\hline \multirow[t]{2}{*}{ Characteristics } & \multirow[t]{2}{*}{ Cases } & \multicolumn{2}{|c|}{ Duration of IM therapy(months) } & \multirow[t]{2}{*}{$P$ value } \\
\hline & & $\leq 8.96$ & $\triangle 8.96$ & \\
\hline Age(years)(mean $\pm S D)$ & 25 & $51.29 \pm 10.64$ & $49.45 \pm 15.06$ & 0.725 \\
\hline Gender & & & & 0.973 \\
\hline Male & 16 & 9 & 7 & \\
\hline Female & 9 & 5 & 4 & \\
\hline Classify of preoperative therapy & & & & 1.000 \\
\hline Locally advanced GISTs & 19 & 11 & 8 & \\
\hline Recurrent/metastasis GISTs & 6 & 3 & 3 & \\
\hline Primary localization & & & & 0.350 \\
\hline Stomach+ small intestine & 19 & 12 & 7 & \\
\hline Rectum+ pelvic/retroperitoneal & 6 & 2 & 4 & \\
\hline Dose of IM therapy & & & & 1.000 \\
\hline $400 \mathrm{mg} / \mathrm{d}$ & 22 & 12 & 10 & \\
\hline $600 \mathrm{mg} / \mathrm{d}$ & 3 & 2 & 1 & \\
\hline Response to IM therapy(according to Choi criteria) & & & & 1.000 \\
\hline PR & 24 & 13 & 11 & \\
\hline SD & 1 & 1 & 0 & \\
\hline
\end{tabular}

\section{Other Influencing Factors}

In our study, including KIT exon 11, 13, and 17 mutation GISTs, which were truly well responsive to imatinib therapy at a dosage of 400 mg daily, KIT exon 9 mutation GISTs were also well responsive to imatinib therapy at a dosage of $600 \mathrm{mg}$ daily, with obvious shrinkage of their tumor size. Two patients with wildtype GISTs showed variable responses to imatinib. One patient showed a good response at a dosage of $400 \mathrm{mg}$ daily, and the other showed an SD response to imatinib. The latter patient underwent surgery after 4 months, received preoperative IM therapy and finally showed recurrence at 26 months after surgery; sunitinib (50 mg daily) was administered immediately after recurrence was detected.

Moreover, we investigated the influence of tumor location with IM therapy; we divided all GIST patients into gastric GIST (G-GIST) and non-gastric GIST (NGGIST) groups. We found that the G-GIST group seemed to have a better tumor size reduction $(4.04 \pm 1.81 \mathrm{~cm}$ vs $2.70 \pm 2.11, \mathrm{P}=0.102)$ and a reduced percentage $(34.15 \% \pm 17.77 \%$ vs $29.81 \% \pm 16.41 \%, P=0.537)$; however, we found that the G-GIST group achieved a better decrease in tumor density (HU) ( 18.64 \pm 6.12 vs $12.54 \pm 5.75, \mathrm{P}=0.018)$ and decreased percentage of tumor density $(\mathrm{HU})(28.88 \% \pm 8.94 \%$ vs $20.57 \% \pm 8.82 \%, \mathrm{P}=0.030)(\mathrm{Fig} .4)$, which suggested that gastric GISTs had a better response to IM preoperative therapy than non-gastric GISTs.

\section{Prognosis Of Preoperative IM Therapy Patients}


The follow-up period ranged from 27 to 132 months with a median period of 55.12 months from the onset of preoperative IM therapy (Fig. 5). One patient failed to follow-up at 48 months (42 months after surgery). The 2-year PFS and 5-year PFS were $92 \%$ and $60 \%$, respectively, and the total 5-year cancerspecific survival (CSS) was $92 \%$. One patient died at 48 months (41 months after surgery) because of tumor progression and refusal of any IM or other TKIs while exhibiting disease progression.

\section{Discussion}

GIST is the most common mesenchymal tumor occurring in the digestive tract and originates from mesenchymal stem cells (interstitial cells of Cajal) [2]. With the unstable biological behavior of GISTs, and because traditional chemotherapy and radiotherapy seem to have no effect on GISTs, surgery may be the only way to cure this disease, in approximately $60 \%$ of GIST patients with localized GISTs [3]. In addition, up-front surgery for tumor resection should be deeply considered in cases requiring extensive organ resections for R0 resection, especially total gastrectomy, pancreaticoduodenectomy or abdominoperineal excision, which might eventually lead to permanent changes in lifestyle or increase the incidence of surgical complications. Preoperative treatment is beneficial for those patients and for patients with unresectable GIST. In particular, mutation analysis has shown that TKIs are sensitive to IM treatment and can reduce the GIST cell population, which finally reduces the tumor size, may facilitate RO resection and can reserve the structure and function of target organs to the greatest extent[18]. Moreover, IM therapy before the operation can decrease the risk of bleeding, postoperative complications and tumor rupture during the operation, leading to a lower possibility of tumor cell dissemination [19]. Several studies have shown that locally advanced, unresectable and recurrent/metastatic GIST patients may benefit from preoperative adjuvant IM therapy. For example, Sumin Tang found that patients with preoperative IM treatment can receive more extensive R0 resection of tumors and lower surgical morbidity in large GISTs, with a median length of 12 months of preoperative IM treatment[20]. Tielen R et al found that preoperative IM treatment was feasible in locally advanced GISTs, with a median decrease of $50 \%$ in tumor size in 57 patients and a median IM duration of 32 weeks. Moreover, preoperative IM treatment combined with surgery improved PFS and OS in those patients[21]. Those studies recommended the feasibility and effectiveness of preoperative IM treatment; hence, the latest European Society for Medical Oncology (ESMO) and National Comprehensive Cancer Network (NCCN) guidelines recommended preoperative IM treatment as an effective treatment for these special patients[22, 23]. However, there is still controversy regarding which Jin-Chiao Lee et al indicated that caution should be taken when dealing with preoperative IM therapy because it might jeopardize anastomotic healing of the bowel and increase the postoperative complications in those patients[24]. In our study, we found that 25 enrolled patients, including 18 locally advanced GISTs and 7 recurrent/metastatic GISTs, responded well to preoperative IM treatment and had 1 SD status and 24 PR status, with $96 \%$ patients having a decrease in tumor size. Moreover, all the patients well tolerated IM therapy, and none of them had complications after tumor resection, indicating that preoperative IM therapy was still feasible for locally advanced GISTs and recurrent/metastatic GISTs, especially for patients with unresectable tumors or needing extensive R0 organ resection.

Gene mutation analysis plays a critical role in the patient plan for IM therapy because patients with advanced and recurrent/metastasis have different responses to imatinib, and the aim of preoperative IM therapy is to downstage the current situation of GIST patients, which depends on the responses to IM therapy. Gene mutation analysis can help clinicians formulate individualized precision-medicine plans for GIST patients, and most GISTs have KIT mutations occurring in exons $9,11,13$, and 17 and PDGFRA mutations occurring in exons 12, 14 and 18[8, 9]. Patients with KIT exon 11 mutations, including deletion and duplication, seem to benefit most and respond well to imatinib, so it is generally advised that at a dosage of $400 \mathrm{mg}$ daily, European patients with KIT exon 9 mutations are still sensitive to imatinib but need $400 \mathrm{mg}$ twice daily[8, 22, 23]. However, Chinese patients are usually intolerant, and as a consequence, the dosage of IM in China is $600 \mathrm{mg}$ administered daily[25], KIT exon 13 and 17 mutations are rare in GISTs. Limited case reports have shown that KIT exon 13 and 17 mutations seem likely to respond to imatinib therapy. Engin $\mathrm{G}$ et al analyzed a familial GIST with 3 KIT exon 13 mutation patients and found that they responded well to imatinib adjuvant therapy at a dosage of $400 \mathrm{mg}$ daily[26]. Similar findings have been found by Heinrich MC et al[27] and DebiecRychter M et al[28]. Patients with KIT exon 17 mutations can rarely be detected in GISTs, and their response to imatinib is variable; in most cases, they respond well to imatinib therapy[29-31]. In addition, approximately $10 \%$ of GIST patients have no mutation in either KIT or PDGFRA, and these tumors are called wild-type GISTs and have an approximately $0-45 \%$ likelihood of a response to imatinib[8, 23]. To date, all the reported phase II trials of preoperative treatment did not include mutational analysis as a prerequisite for neoadjuvant treatment. In our study, we tested all the gene mutations in GIST patients who were going to take preoperative IM therapy, and the results showed that GISTs with KIT exon 11, 13, and 17 mutations truly responded well to imatinib therapy at a dosage of $400 \mathrm{mg}$ daily. GISTs with KIT exon 9 mutations also responded well to imatinib therapy at a dosage of 600 mg daily, with obvious shrinkage of their tumor size. Two patients with wild-type GISTs showed variable responses to imatinib. One patient showed a good response at a dosage of 400 mg daily; the other patient showed an SD response to imatinib, underwent surgery after 4 months of preoperative IM therapy, and finally exhibited recurrence at 26 months after surgery and received sunitinib (50 mg daily) immediately after the recurrence was detected. Our results indicated that mutation analysis is strongly recommended before preoperative IM therapy in order to formulate an individualized and precision medicine plan for the patients.

The optimal duration of preoperative IM therapy remains controversial because it the optimal operation window might be missed if patients take long-term imatinib therapy, which would finally lead to resistance to IM therapy and promote tumor progression. Short-term imatinib therapy generally achieves a finite efficient shrinkage of tumor size. To date, several studies have been performed to probe the appropriate duration of preoperative IM therapy; these results are inconsistent, and the duration varies considerably. The RTOG 0132/ACRIN 6665 clinical trial including 31 primary GIST patients and 22 recurrent/metastatic GIST patients performed effective preoperative IM treatment after a duration of 8 to 12 weeks (median, 9.9 weeks) at a dosage of 600 mg daily, and the 5-year PFS and OS were $46.1 \%$ and $73.6 \%$, respectively[32]. Another phase III study (B2222) indicated that most preoperative IM therapies for unresectable/metastatic GISTs required a duration of 5.3 months to obtain a good response [33]. A Japanese phase II study (STI571B1202) proved that a plateau response of preoperative IM therapy for unresectable/metastatic GISTs needs 200 days[34]. With such studies focusing on the optimal duration of preoperative IM therapy, the latest ESMO guidelines recommend a duration of 6 to 12 months while initiating IM therapy and following surgical intervention [22]. The NCCN guidelines recommend a duration of at least 6 months to obtain the maximal response[23]. In our study, we performed surgery after a median time of 8.96 months to obtain a plateau response (ranging from 3 to 26 months), which was longer than that in the RTOG 0132/ACRIN 6665 clinical trial and B2222 trial but similar to that in the STI571B1202 study. We also found that different locations had their respective durations and plateau responses to IM 
therapy, as follows; extra-GI (12.5 months), rectum (10.0 months), stomach (8.64 months) and small intestine (7.60 months). In addition, even one patient remained sensitive to IM after 26 months of initiation preoperative IM therapy. Hence, there are individual differences at the duration of preoperative IM therapy, but most achieved the best beneficial response at a median duration of 8.96 months.

Interestingly, we found that tumor location in the upper gastrointestinal tract, especially in the stomach, had a better response to preoperative IM therapy than did non-gastric GISTs. A Japanese-Korean UMIN00000003114 study included gastric GISTs larger than $10 \mathrm{~cm}$, and other localizations were not included, with $400 \mathrm{mg}$ imatinib for 6-9 months. The results showed that none of the 53 patients developed tumor progression, $62 \%$ achieved a PR response, and all patients achieved a good response to preoperative IM therapy, suggesting that neoadjuvant imatinib therapy can be beneficial for larger gastric GISTs, which was similar to our research[35]. However, few studies have focused on the influence of tumor localization in preoperative IM therapy. Our results recommended that gastric GISTs might have a better response to preoperative IM therapy, and if tumors were nongastric, especially in the rectum, the response might be worse, and a longer duration was suggested for patients undergoing preoperative IM therapy.

It should be stressed that, first, this was a retrospective study, so we cannot compare the outcomes of patients undergoing extensive surgery without preoperative IM therapy to those of patients undergoing surgery with neoadjuvant IM therapy, as ESMO and NCCN guidelines recommend that neoadjuvant IM therapy provides a benefit and a better quality of life for those patients. Second, our study group was a small-scale sample, and our study was a nonrandomized controlled trial, so it is difficult to obtain any definitive conclusion, including the exact, optimal duration of preoperative IM therapy. Further randomized controlled trials and prospective studies should be performed. From our recent study results, we suggest that preoperative IM therapy is a recommendable strategy for locally advanced and recurrent/metastatic GISTs.

\section{Conclusion}

Preoperative IM therapy is a feasible method for locally advanced and recurrent/metastatic GISTs. Mutation analysis should be performed before IM therapy, and the initial dosage of IM should be based on the results of the mutation analysis. Although there are individual differences in the duration of preoperative IM therapy, it mostly has a median time of 8.96 months. Moreover, gastric GISTs have a better response to preoperative IM therapy than do non-gastric GISTs.

\section{Declarations}

\section{Ethics approval and consent to participate}

The research was supported by the Medical Ethical Committee of Xiangya Hospital, Central South University (No. 201909812).

\section{Consent for publication}

Not applicable.

\section{Availability of data and materials}

The raw data underlying this paper are available upon request to the corresponding author due to ethical restrictions.

\section{Competing interests}

The authors declare that they have no competing interests.

\section{Funding}

This study was supported by the Natural Science Foundation of Hunan Province, China (Grant No. 2017JJ2380).

\section{Authors' contributions}

Conceived and designed the experiments: LGQ

Analyzed the data: QJ, LGQ. Performed the experiments: QJ, LS, RF, SW, LWH, CGQ.

Wrote the paper: QJ, LGQ. All authors read and approved the final manuscript.

\section{Acknowledgments}

Not applicable

\section{References}

[1]. Cassier, P.A., et al., A prospective epidemiological study of new incident GISTs during two consecutive years in Rhone Alpes region: incidence and molecular distribution of GIST in a European region. Br J Cancer, 2010. 103(2): p. 165-70.

[2]. Joensuu, H., P. Hohenberger and C.L. Corless, Gastrointestinal stromal tumour. Lancet, 2013. 382(9896): p. $973-83$. 
[3]. Joensuu, H., et al., Risk of recurrence of gastrointestinal stromal tumour after surgery: an analysis of pooled population-based cohorts. Lancet Oncol, 2012. 13(3): p. 265-74.

[4]. Emile, J.F., et al., Frequencies of KIT and PDGFRA mutations in the MolecGIST prospective population-based study differ from those of advanced GISTs. Med Oncol, 2012. 29(3): p. 1765-72.

[5]. Zhang, L., et al., Gastric stromal tumors in Carney triad are different clinically, pathologically, and behaviorally from sporadic gastric gastrointestinal stromal tumors: findings in 104 cases. Am J Surg Pathol, 2010. 34(1): p. 53-64.

[6]. Medeiros, F., et al., KIT-negative gastrointestinal stromal tumors: proof of concept and therapeutic implications. Am J Surg Pathol, 2004. 28(7): p. 889-

94.

[7]. West, R.B., et al., The novel marker, DOG1, is expressed ubiquitously in gastrointestinal stromal tumors irrespective of KIT or PDGFRA mutation status. Am J Pathol, 2004. 165(1): p. 107-13.

[8]. Joensuu, H., et al., KIT and PDGFRA mutations and the risk of GI stromal tumor recurrence. J Clin Oncol, 2015. 33(6): p. 634-42.

[9]. Hirota, S., et al., Gain-of-function mutations of c-kit in human gastrointestinal stromal tumors. Science, 1998. 279(5350): p. 577-80.

[10]. Rubin, B.P., Gastrointestinal stromal tumours: an update. Histopathology, 2006. 48(1): p. 83-96.

[11]. Tran, T., J.A. Davila and H.B. El-Serag, The epidemiology of malignant gastrointestinal stromal tumors: an analysis of 1,458 cases from 1992 to 2000. Am J Gastroenterol, 2005. 100(1): p. 162-8.

[12]. Verweij, J., et al., Imatinib mesylate (STI-571 Glivec, Gleevec) is an active agent for gastrointestinal stromal tumours, but does not yield responses in other soft-tissue sarcomas that are unselected for a molecular target. Results from an EORTC Soft Tissue and Bone Sarcoma Group phase II study. Eur J Cancer, 2003. 39(14): p. 2006-11.

[13]. Corless, C.L., et al., Pathologic and molecular features correlate with long-term outcome after adjuvant therapy of resected primary GI stromal tumor: the ACOSOG Z9001 trial. J Clin Oncol, 2014. 32(15): p. 1563-70.

[14]. Casali, P.G., et al., Time to Definitive Failure to the First Tyrosine Kinase Inhibitor in Localized GI Stromal Tumors Treated With Imatinib As an Adjuvant: A European Organisation for Research and Treatment of Cancer Soft Tissue and Bone Sarcoma Group Intergroup Randomized Trial in Collaboration With the Australasian Gastro-Intestinal Trials Group, UNICANCER, French Sarcoma Group, Italian Sarcoma Group, and Spanish Group for Research on Sarcomas. J Clin Oncol, 2015. 33(36): p. 4276-83.

[15]. Wang, S.Y., et al., Prospective Evaluation of Neoadjuvant Imatinib Use in Locally Advanced Gastrointestinal Stromal Tumors: Emphasis on the Optimal Duration of Neoadjuvant Imatinib Use, Safety, and Oncological Outcome. Cancers (Basel), 2019. 11(3).

[16]. Haller, F., et al., Surgical management after neoadjuvant imatinib therapy in gastrointestinal stromal tumours (GISTs) with respect to imatinib resistance caused by secondary KIT mutations. Ann Surg Oncol, 2007. 14(2): p. 526-32.

[17]. Choi, H., et al., Correlation of computed tomography and positron emission tomography in patients with metastatic gastrointestinal stromal tumor treated at a single institution with imatinib mesylate: proposal of new computed tomography response criteria. J Clin Oncol, 2007. 25(13): p. 1753-9.

[18]. Raut, C.P., et al., Surgical management of advanced gastrointestinal stromal tumors after treatment with targeted systemic therapy using kinase inhibitors. J Clin Oncol, 2006. 24(15): p. 2325-31.

[19]. Miettinen, M. and J. Lasota, Gastrointestinal stromal tumors: pathology and prognosis at different sites. Semin Diagn Pathol, $2006.23(2)$ : p. 70-83.

[20]. Tang, S., et al., Preoperative imatinib mesylate (IM) for huge gastrointestinal stromal tumors (GIST). World J Surg Oncol, 2017. $15(1)$ : p. 79.

[21]. Tielen, R., et al., Surgical treatment of locally advanced, non-metastatic, gastrointestinal stromal tumours after treatment with imatinib. Eur J Surg Oncol, 2013. 39(2): p. 150-5.

[22]. Casali, P.G., et al., Gastrointestinal stromal tumours: ESMO-EURACAN Clinical Practice Guidelines for diagnosis, treatment and follow-up. Ann Oncol, 2018. 29(Suppl 4): p. iv267.

[23]. von Mehren, M., et al., Soft Tissue Sarcoma, Version 2.2018, NCCN Clinical Practice Guidelines in Oncology. J Natl Compr Canc Netw, 2018. 16(5): p. 536-563.

[24]. Lee, J.C., et al., Preoperative tyrosine kinase inhibitors risks bowel anastomotic healing in patients with advanced primary and recurrent/metastatic gastrointestinal stromal tumors-- A rose has its thorns. Eur J Surg Oncol, 2019. 45(2): p. 153-159.

[25]. Li, J., et al., Efficacy of imatinib dose escalation in Chinese gastrointestinal stromal tumor patients. World J Gastroenterol, 2012. 18(7): p. 698-703.

[26]. Engin, G., et al., Imatinib response of gastrointestinal stromal tumor patients with germline mutation on KIT exon 13: A family report. World J Radiol, 2017. 9(9): p. 365-370. 
[27]. Heinrich, M.C., et al., Kinase mutations and imatinib response in patients with metastatic gastrointestinal stromal tumor. J Clin Oncol, 2003. 21(23): p. 4342-9.

[28]. Debiec-Rychter, M., et al., KIT mutations and dose selection for imatinib in patients with advanced gastrointestinal stromal tumours. Eur J Cancer, 2006. 42(8): p. 1093-103.

[29]. Xu, C.W., et al., Analysis of mutation of the c-Kit gene and PDGFRA in gastrointestinal stromal tumors. Exp Ther Med, 2015. 10(3): p. $1045-1051$.

[30]. Spitaleri, G., et al., Inactivity of imatinib in gastrointestinal stromal tumors (GISTs) harboring a KIT activation-loop domain mutation (exon 17 mutation pN822K). Onco Targets Ther, 2015. 8: p. 1997-2003.

[31]. Hanson, J.A., et al., Small-intestinal rhabdoid gastrointestinal stromal tumor (GIST): mutation analysis and clinical implications of a rare morphological variant. Int J Surg Pathol, 2011. 19(5): p. 653-7.

[32]. Wang, D., et al., Phase II trial of neoadjuvant/adjuvant imatinib mesylate for advanced primary and metastatic/recurrent operable gastrointestinal stromal tumors: long-term follow-up results of Radiation Therapy Oncology Group 0132. Ann Surg Oncol, 2012. 19(4): p. 1074-80.

[33]. Blanke, C.D., et al., Long-term results from a randomized phase II trial of standard- versus higher-dose imatinib mesylate for patients with unresectable or metastatic gastrointestinal stromal tumors expressing KIT. J Clin Oncol, 2008. 26(4): p. 620-5.

[34]. Nishida, T., et al., Efficacy and safety profile of imatinib mesylate (ST1571) in Japanese patients with advanced gastrointestinal stromal tumors: a phase II study (STI571B1202). Int J Clin Oncol, 2008. 13(3): p. 244-51.

[35]. Kurokawa, Y., et al., Phase II study of neoadjuvant imatinib in large gastrointestinal stromal tumours of the stomach. Br J Cancer, 2017. 117(1): p. 2532.

\section{Figures}

29 patients were enrolled

1 patient ineligible due to rejecting research

28 patients were eligible

1 patient did not start the IM therapy due to PDGFRA exon $18 \mathrm{D} 842 \mathrm{~V}$ mutation

\section{7 patients performed the preoperative IM therapy}

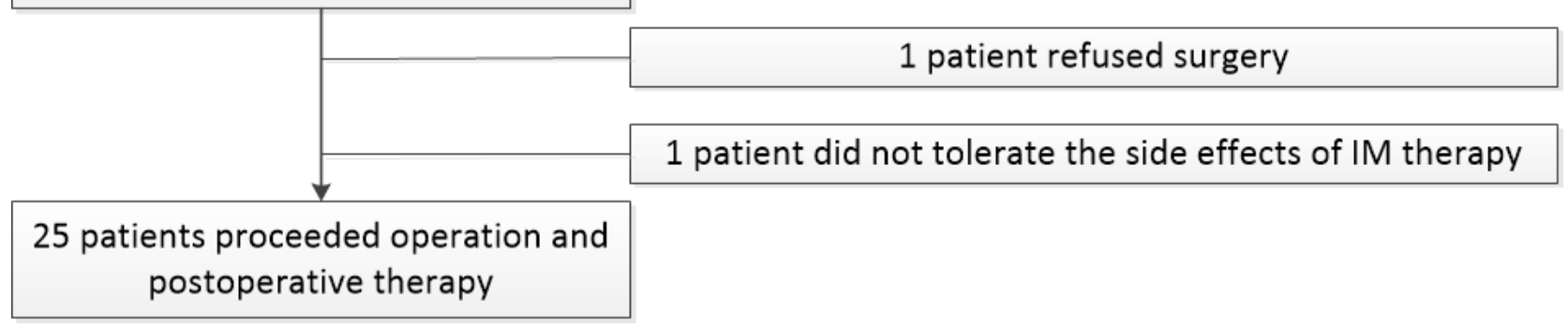

Figure 1

Study profile. PDGFRA, platelet-derived growth factor receptor alpha; IM, imatinib mesylate. 


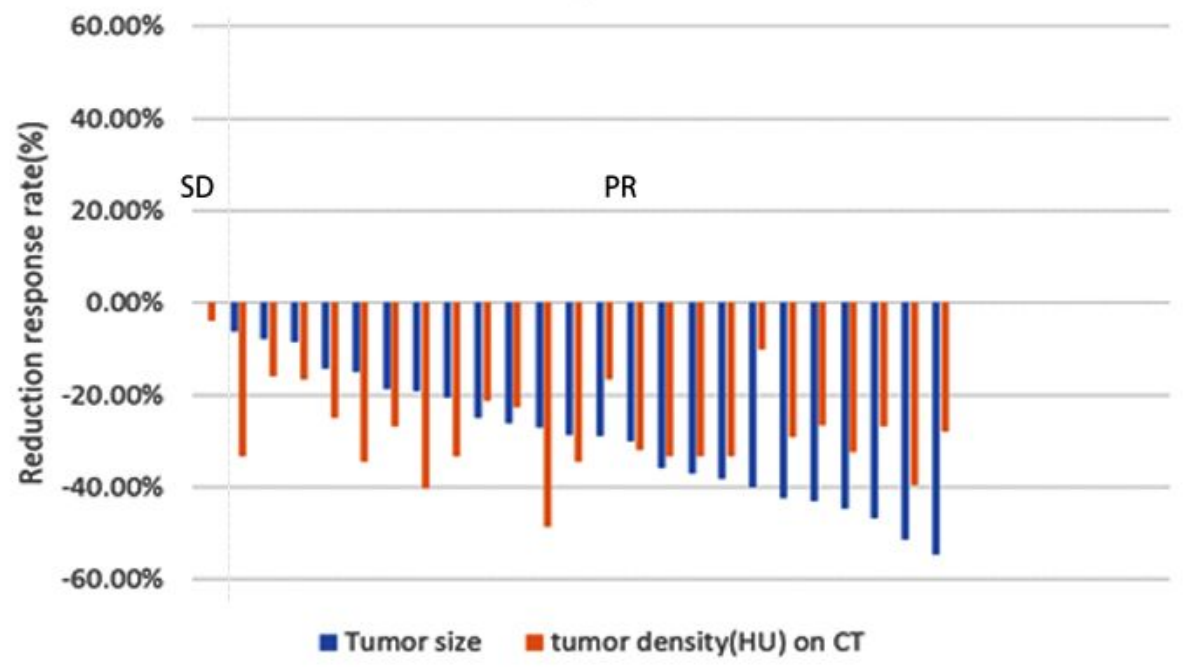

Figure 2

Waterfall plot of the ranked best tumor shrinkage after preoperative IM therapy.
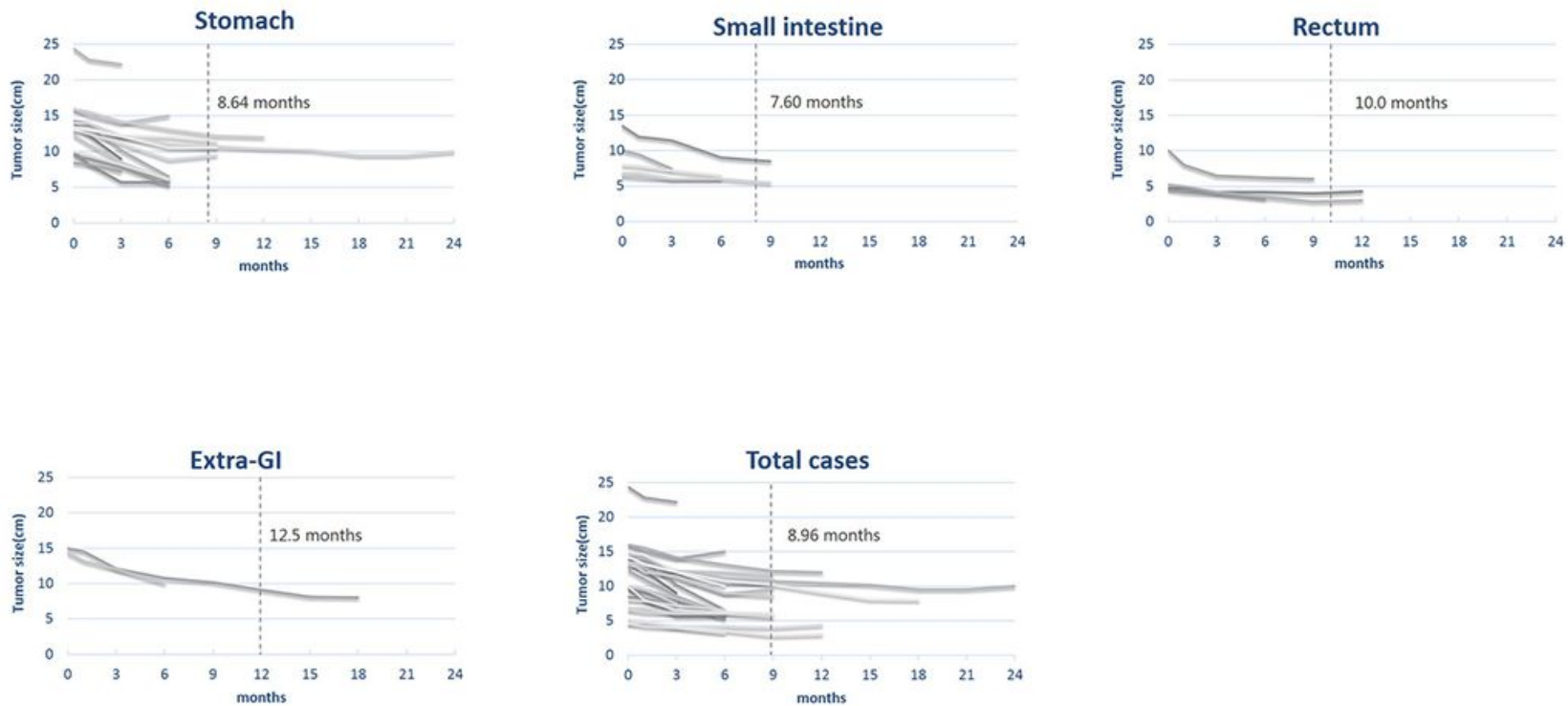

Figure 3

Change in tumor sizes after the initiation of IM therapy: stomach, small intestine, rectum, extra-GI and total cases. 


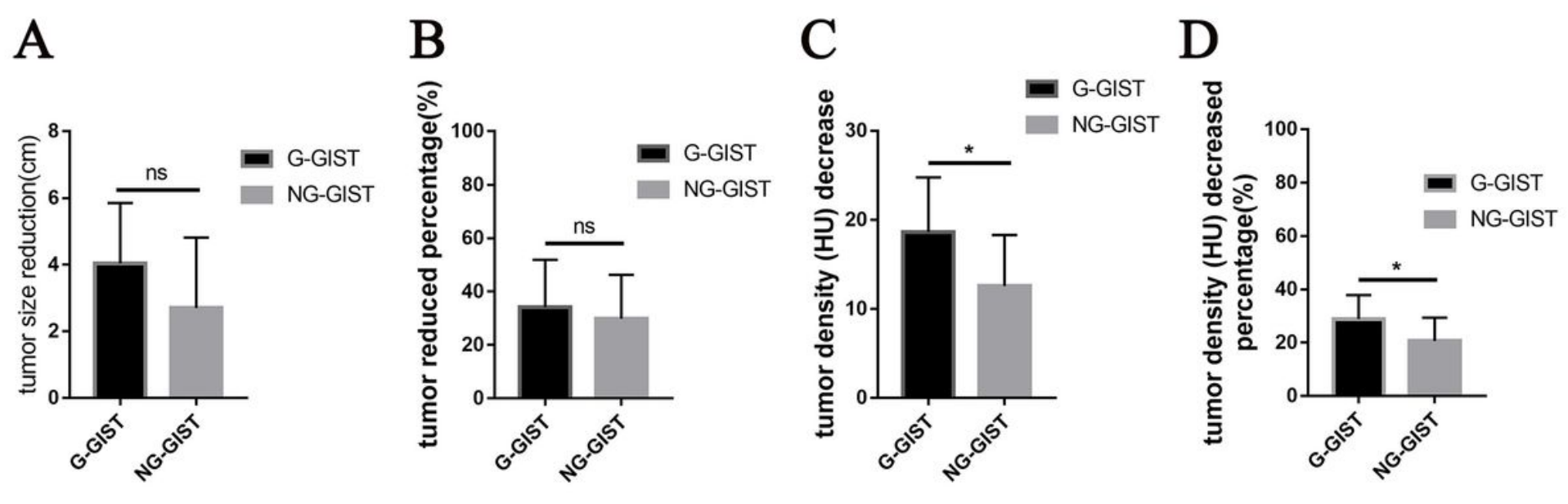

Figure 4

Response to preoperative IM therapy for gastric GISTs (G-GISTs) and non-gastric GISTs (NG-GISTs) (A-D): tumor size reduction, tumor reduced percentage, tumor density $(\mathrm{HU})$ decrease and tumor density $(\mathrm{HU})$ decreased percentage.

A

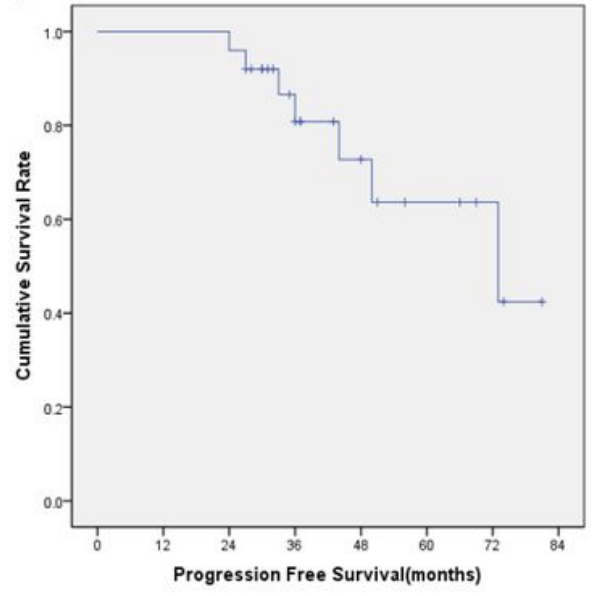

B

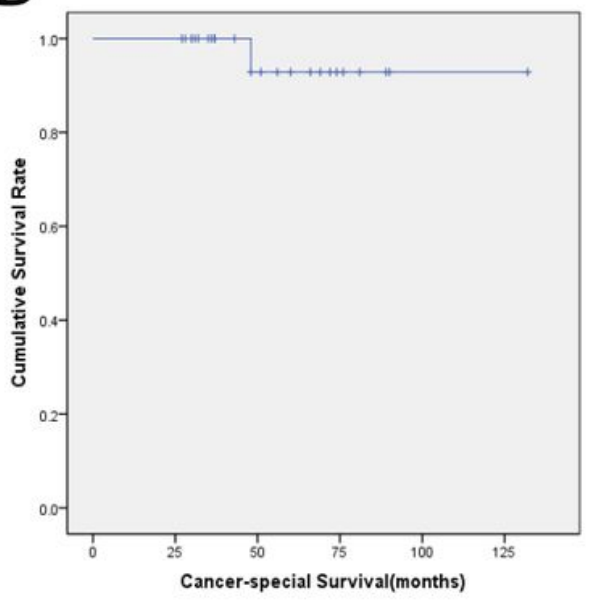

\section{Figure 5}

Progression-free survival (A) and cancer-specific survival (B) of patients treated with preoperative IM therapy, followed by surgery and postoperative IM therapy. 